\author{
Asian Journal of \\ Medical and Biological Research \\ ISSN 2411-4472 (Print) 2412-5571 (Online) \\ www.ebupress.com/journal/ajmbr
}

\title{
Article \\ Discriminate and indiscriminate use of amoxicillin and its effects on hematological parameters of broiler
}

\author{
Md. Shakil Islam, Md. Zahorul Islam and Md. Shafiqul Islam* \\ Department of Pharmacology, Bangladesh Agricultural University, Mymensingh-2202, Bangladesh
}

*Corresponding author: Professor Dr. Md. Shafiqul Islam, Department of Pharmacology, Bangladesh Agricultural University, Mymensingh-2202, Bangladesh. E-mail: shafiqpharma@yahoo.co.uk

Received: 06 June 2019/Accepted: 25 June 2019/ Published: 30 June 2019

\begin{abstract}
Hematological indication is an important finding for pathophysiology analysis of biological science. This study was designed with the aim to investigate the effects of residual antibiotics on hematological parameters of broiler following discriminate and indiscriminate use. Broiler chicks were reared accordingly upto 30 days and on day 14 the chicks were randomly divided into 3 groups (n=6) namely control (group A), discriminate (group B) and indiscriminate (group C). At the age of day 16, amoxicillin treatment was started and continued for seven (7) days for in discriminate group (Group B) and fifteen (15) days for indiscriminate group. In case of discriminate group withdrawal period was properly maintained as nomenclature (Seven days) whereas, there was no withdrawal period in case of indiscriminate group. The hemoglobin (gm\%) of control, discriminate, and indiscriminate group was $7.07 \pm 0.099,6.97 \pm 0.095$, and $6.90 \pm 0.124$; Total erythrocyte count (TEC) $2.55 \pm 0.044$ million $/ \mathrm{mm} 3,2.53 \pm 0.038 \mathrm{million} / \mathrm{mm} 3$, and $2.50 \pm 0.026 \mathrm{million} / \mathrm{mm} 3$; Packed Cell Volume PCV (\%) 19.83 $\pm 1.302,19.33 \pm 1.054$, and $18.50 \pm 0.764$ respectively. There was no significant difference on blood parameter found among the groups. Therefore, discriminate and indiscriminate use of amoxicillin has no bad effect on hematological parameters of broiler.
\end{abstract}

Keywords: amoxicillin; hematological parameters; broilers

\section{Introduction}

In veterinary practices, antibiotics are widely used in different pattern as prophylactic, therapeutic, growth promoter and sometimes both prophylactic and therapeutic purposes all over the world (Guetiya Wadoum et al., 2016). For prevention of diseases, enhancement of growth and feed efficacy, the use of antibiotic is increasing day by day (Singh et al., 2014) and antibiotics are used indiscriminate in poultry industries (Kempe et al., 1999). Amoxicillin is a broad-spectrum, pharmacologically active beta-lactam antibiotic (Koutoulis et al., 2015) used extensively for treatment bacterial infection in poultry industries (Alswayeh et al., 2015; Khan et al., 2018). Although antibiotic therapy and their growth promoting effects are essential in animal production (Prescott, 2008; Persoons et al., 2012); the indiscriminate use of antibiotic is associated with antibiotic residue in food of animal origin related to public health concerns (Donoghue, 2003). Besides, antibiotic therapy is associated with toxic effect on hematopoiesis process causing a change in blood parameter of poultry (Stolker and Brinkman, 2005). Certain antibiotics show diverse effect on different elements of the blood like thrombocytopenia, anemia, leucopenia etc. (Al-Mayah and Al-Ahmed, 2005). Hematological investigations in monitoring the health status of birds has grown in extent, becoming an indispensable component of the protocols used for testing bioequivalence, safety and tolerance of active substances on the target species (Ognean et al., 2004). As, Hematological profile an important physiological indicator of the body associated with animal production (Aboubakr \& Elbadawy, 2016), the present study was undertaken to investigate the effect of amoxicillin antibiotic on hematological parameter of broiler following discriminate and indiscriminate use of amoxicillin. 
2. Materials and Methods

2.1. Experimental design

18 DOCs were collected as laboratory animal. Chicks were reared for 14 days without using any antibiotic; only feed and water. Then chicks were grouped in 3 experimental groups (A, B and C); each group having 10 chicks. Group A was kept as untreated control and received no antibiotic medicated water, group B is discriminate group and group $\mathrm{C}$ is indiscriminate group. Antibiotic treatment was started from 16th day. Group B was administered with amoxicillin at recommended therapeutic dose @ $10 \mathrm{mg} / \mathrm{kg}$ through drinking water as described in (Anadón et al., 1996). In group C the dose of amoxicillin was indiscriminate and more than the therapeutic dose $(10 \mathrm{mg} / \mathrm{kg})$. After 7 days, at the age of day 23 ; antibiotic supply was stopped in the group-B and withdrawal period was maintained as drug nomenclature (7 days). In group $\mathrm{C}$ withdrawal period was not maintained and antibiotic continued till $30^{\text {th }}$ day. Blood sample was collected from every bird at $30^{\text {th }}$ day.

\subsection{Collection of blood samples}

Blood samples from all groups (Control, discriminate \& indiscriminate) were collected into sterile heparinized vials $(2 \mathrm{ml}$ vial) from wing vein and were immediately stored into refrigerator for further use.

\subsection{Determination of hematological parameters}

1. Estimation of Hemoglobin ( $\mathrm{Hb})$ by acid hematin method and expressed as gram (\%).

2. Total Erythrocyte Count (TEC) by hemocytometry method and expressed as million/ $\mathrm{mm}^{3}$

3. Packed cell volume PCV was determined by Macro-hematocrit (wintrobe) method and expressed as percentage.

\subsection{Statistical Analysis}

Statistical analysis was performed by one way ANOVA using Graphpad Prism; version 6. The results were expressed as mean \pm standard error mean (S.E.M).

\section{Results}

\subsection{Effect on blood parameters}

3.1.1. Hemoglobin (gm \%)

Hemoglobin $(\mathrm{gm} \%)$ in different groups of birds is presented in Table 1. The highest HB (\%) was recorded in control group (7.07 \pm 0.099$)$. The HB (gm\%) of discriminate and indiscriminate groups was $6.97 \pm 0.095$ and $6.90 \pm 0.124$ respectively. Hemoglobin (gm\%) among the three different groups (Control, discriminate and indiscriminate antibiotic groups) did not show any significant differences $(\mathrm{P}>0.05 ; \mathrm{P}$ value $=0.552)$.

Figure 1 represents the $\mathrm{HB}(\%)$ of Control, discriminate and indiscriminate groups. The multiple pair wise comparison during one way ANOVA (Bonferroni) showed that there was no significant difference among the control, discriminate and indiscriminate antibiotic groups.

\subsubsection{Total Erythrocyte Count (Million/ $\mathbf{m m}^{3}$ )}

Total Erythrocyte Count in different groups of birds is presented in Table 2. The Total Erythrocyte Count in control group was $2.55 \pm 0.044 \mathrm{million} / \mathrm{mm}^{3}$ whereas; the TEC of discriminate and indiscriminate group was $2.53 \pm 0.038 \mathrm{million} / \mathrm{mm}^{3}$ and $2.50 \pm 0.026 \mathrm{million} / \mathrm{mm}^{3}$ respectively. The highest TEC value was observed in control group and the lowest in indiscriminate group. Total Erythrocyte Count (TEC) among the three different groups (Control, discriminate and indiscriminate) did not show any significant difference $(\mathrm{P}>0.05 ; \mathrm{P}$ value $=$ $0.6204)$.

Figure 2 represents the Total Erythrocyte Count (TEC) of three different groups .The multiple comparisons during one way ANOVA (Bonferroni) showed that there was no significant difference among the control, discriminate and indiscriminate antibiotic groups.

\subsubsection{Packed Cell Volume (PCV) (\%)}

Packed Cell Volume (PCV) (\%) in different groups of birds is presented in Table 3. PCV\% in control group A was $19.83 \pm 1.302$ whereas, in discriminate group it was $19.33 \pm 1.054$ and in indiscriminate group it was $18.50 \pm 0.7638$. The highest mean PCV was obtained from control group and lowest from indiscriminate group. Packed Cell Volume (PCV) among the three different groups (Control, discriminate and indiscriminate) did not show any significant difference $(\mathrm{P}>0.05 ; \mathrm{P}=0.676)$. 
Figure 3 represents the Packed Cell Volume (PCV) of Control, discriminate and indiscriminate groups. The multiple pair wise comparison during one way ANOVA (Bonferroni) showed that there was no significant difference among the control, discriminate and indiscriminate antibiotic groups.

Table 1. Hemoglobin (gm\%) of three individual groups.

\begin{tabular}{llll}
\hline Name of group & $\begin{array}{l}\text { Hemoglobin } \\
\text { SEM) }\end{array}$ & (Mean \pm P Value & $\begin{array}{l}\text { Level of } \\
\text { Significance }\end{array}$ \\
\hline Group-A (Control group) & $7.067 \pm 0.099$ & & \\
Group-B (Discriminate group) & $6.967 \pm 0.095$ & \multirow{2}{*}{0.552} & $\mathrm{~ns}$ \\
Group-C (Indiscriminate group) & $6.900 \pm 0.124$ & & \\
\hline
\end{tabular}

$\mathrm{ns}=$ Nonsignificant

Table 2. Total Erythrocyte Count (TEC) $\left(\right.$ Million $\left./ \mathrm{mm}^{3}\right)$ of three individual groups.

\begin{tabular}{llll}
\hline Name of group & $\begin{array}{l}\text { TEC }\left(\text { Million/ } \mathbf{m m}^{3}\right) \\
(\text { Mean } \pm \text { SEM) }\end{array}$ & P Value & $\begin{array}{l}\text { Level of } \\
\text { Significance }\end{array}$ \\
\hline Group-A (Control group) & $2.553 \pm 0.044$ & & \\
Group-B (Discriminate group) & $2.528 \pm 0.038$ & 0.6204 & $\mathrm{~ns}$ \\
Group-C (Indiscriminate group) & $2.502 \pm 0.026$ & & \\
\hline
\end{tabular}

ns= Nonsignificant

Table 3. Packed Cell Volume (PCV) (\%) of three individual groups.

\begin{tabular}{lccc}
\hline Name of group & PCV \% (Mean \pm SEM) & P Value & $\begin{array}{l}\text { Level of } \\
\text { Significance }\end{array}$ \\
\hline Group-A (Control group) & $19.83 \pm 1.302$ & $\mathrm{~ns}$ \\
Group-B (Discriminate group) & $19.33 \pm 1.054$ & 0.676 & \\
Group-C (Indiscriminate group) & $18.50 \pm 0.764$ & & \\
\hline
\end{tabular}

ns= Nonsignificant

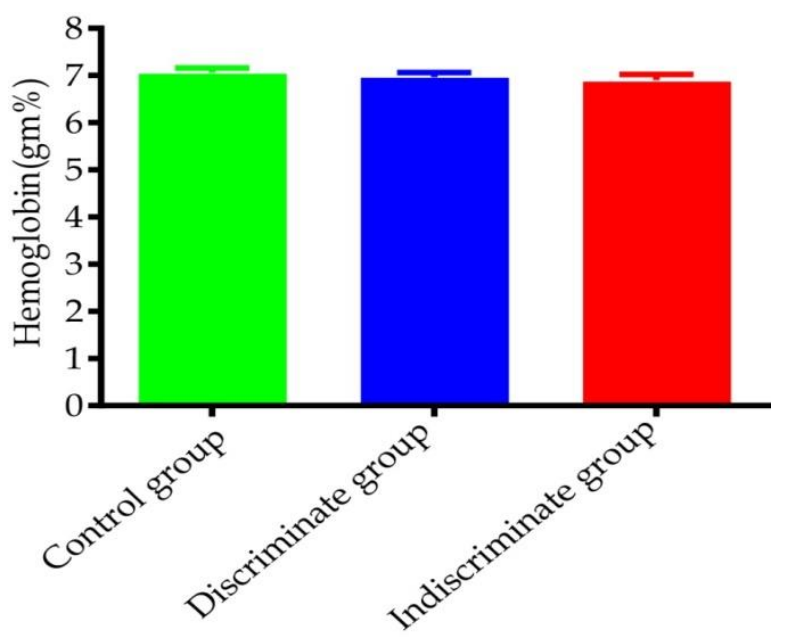

Figure 1. HB (gm\%) of three individual groups.

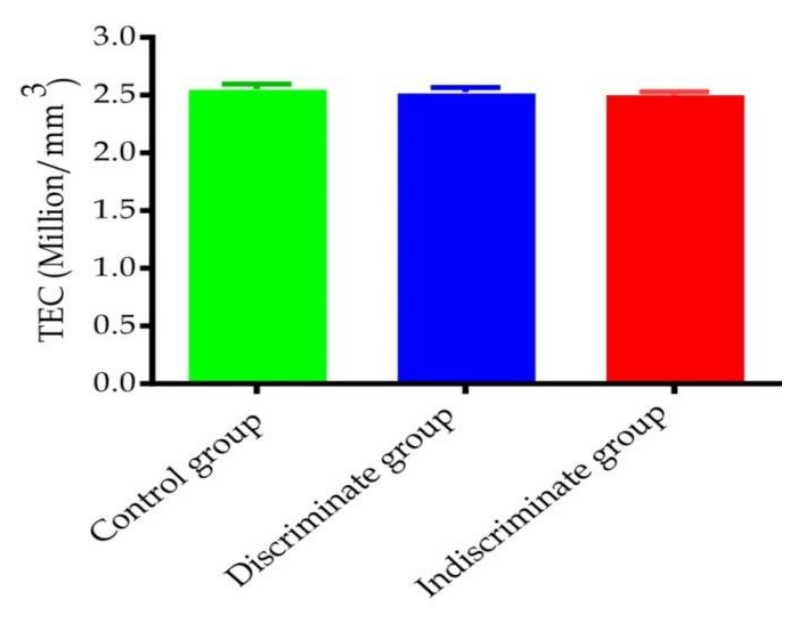

Figure 2. Total Erythrocyte Count (Million/mm3) of three individual groups. 


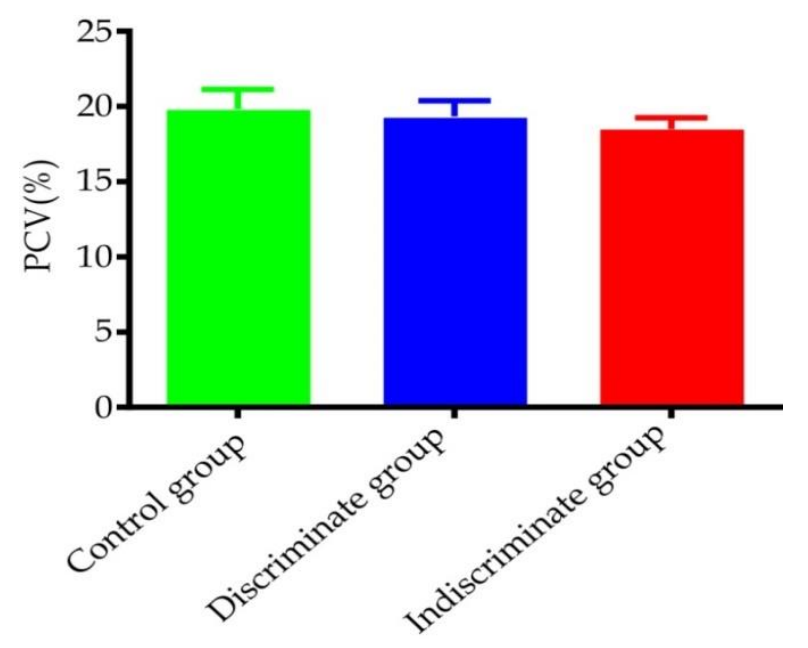

Figure 3. Packed Cell Volume (PCV) three individual groups.

\section{Discussion}

The hemoglobin percentage at the end of the experiment was higher in the control group than the discriminate and indiscriminate groups, but the discriminate and indiscriminate use of amoxicillin didn't show any significant difference on hematological parameters among the groups. This finding is similar to Khan et al. (2018) who reported that hemoglobin level of amoxicillin treated birds @ $20 \mathrm{mg} / \mathrm{Kg}$ orally for consecutive 14 days and @10 mg/Kg orally for consecutive 14 days increased non-significantly compared to control birds. Turcu et al. (2011) also reported that hemoglobin level increased non-significantly in layer hen following Amoxicillin soluble powder (50\%) treatment compared to control birds.

Total Erythrocyte Count (TEC) was height in control and lowest in indiscriminate group. Total Erythrocyte Count was recorded in three individual group didn't show any significant difference among means. The present finding is similar to previous experiment of Ognean (2011) who reported that Total Erythrocyte Count decreased in broilers after erythrocyte treatment (recommended dose and double dose of recommended erythromycin), but no potential risks associated with doubling the dose of erythromycin. Trîncă et al. (2015) reported that mean total number of erythrocytes was highest in control group compared to Oxytetracycline treated birds. Statistical analysis did not show significant differences between the investigated groups. Turcu $e t$ al. (2011) also showed in his experiment that total erythrocyte count was statistically non-significant between control and antibiotic treated groups.

The Packed Cell Volume (PCV) was highest in the control group. But indiscriminate and discriminate groups showed lower mean than the control group. The PCV (\%) of three groups was not statistically significant and multiple pairwise comparisons during one way ANOVA showed that there was no statistical significance among discriminate, indiscriminate and control groups. The result of the study is the reflection of Al-Mayah and AlAhmed (2005) who reported that antibiotic treatment during 22-27 days of age numerically decrease Packed Cell Volume in comparison with control group but the differences are not significant.

\section{Conclusions}

Discriminate and indiscriminate use of amoxicillin has some effects on hematological parameters but the effects are not significant in small duration. The result of the hematological monitoring show that within a short period no potential risks associated with indiscriminate dose of amoxicillin. The result also showed that broiler chickens could tolerate more than the recommended dose of amoxicillin without any deleterious effect on the hematological parameter.

\section{Acknowledgement}

We would like express our gratitude and great pleasure to Department of Pharmacology, Bangladesh Agricultural University (BAU) to execute this research work.

\section{Conflict of interest}

None to declare. 


\section{References}

Aboubakr M and M Elbadawy, 2016. Efficacy of flagymox ${ }^{\circledR}$ (amoxicillin and metronidazole combination) in controlling clostridium perfringens infection in broiler chickens. World Journal of Pharmacy and Pharmaceutical Sci., 6: 80-95.

Al-Mayah AA and JA Al-Ahmed, 2005. Influence of antibiotics treatment on hematological aspect in chicken. Int. J. Poul Sci., 4: 323-325.

Alswayeh R, SN Alvi and MM Hammami, 2015. Rapid determination of amoxicillin level in human plasma by high performance liquid chromatography. WJPPS, 4: 1657-1667.

Anadón A, M Martinez-Larrañaga, M Diaz, P Bringas, M Fernandez, M Martinez and M Fernandez-Cruz, 1996. Pharmacokinetics of amoxicillin in broiler chickens. Avian Pathol., 25: 449-458.

Donoghue DJ, 2003. Antibiotic residues in poultry tissues and eggs: human health concerns? Poult. Sci., 82: 618-621.

Guetiya Wadoum R, N Zambou, F Anyangwe, J Njimou, M Coman, M Verdenelli and A Cresci, 2016. Abusive use of antibiotics in poultry farming in Cameroon and the public health implications. Br. Poult. Sci., 57: 483493.

Kempe M, J Cederfur, M Zihui, Y Pei, UJ Wistrand, GC Fiaccabrino and E Benito, 1999. CREAM — Cartridges with Molecularly Imprinted Recognition Elements for Antibiotic residues Monitoring in Milk. Lunds Universitet, Centre for Chemistry and Chemical Engineering.

Khan M, U Sarkar and TK Mandal, 2018. Effect of amoxicillin on haematobiochemical parameters in poultry. Int. J. Livest. Res., 8: 43-51.

Koutoulis K, I Pappas, G Filioussis and L Athanasiou, 2015. Pharmacokinetics and clinical assessment of amoxicillin for the control of necrotic enteritis in broiler-breeders under field conditions. Avian Biol. Res., 8: 89-96.

Ognean L, V Chiurciu, C Cernea, S Trîncă and R Oroian, 2011. The evaluation of therapeutic doses of erythromycin on the main hematological parameters of broiler chickens. Bulletin of the University of Agricultural Sciences \& Veterinary Medicine Cluj-Napoca. Vet. Med., 68: 277-283.

Persoons D, J Dewulf, A Smet, L Herman, M Heyndrickx and A Martel, 2012. Antimicrobial use in Belgian broiler production. Prev. Vet. Med., 105: 320-325.

Prescott JF, 2008. Antimicrobial use in food and companion animals. Anim. Health Res. Rev., 9: 127-133.

Singh S, S Shukla, N Tandia, N Kumar and R Paliwal, 2014. Antibiotic residues: a global challenge. Pharma. Sci. Monitor, 5: 184-197.

Stolker A and UT Brinkman, 2005. Analytical strategies for residue analysis of veterinary drugs and growthpromoting agents in food-producing animals - a review. J. Chromatogr. A, 1067: 15-53.

Trîncă S, L Ognean, V Chiurciu, C Chiurciu, A Arion and I Dumitru, 2015. The influence of different doses of oxytetracycline on some hematological parameters in broilers. Bulletin UASVM Veterinary Medicine, 72: $19-22$

Turcu D, M Oporanu, P Grigorescu and M Roman, 2011. Studii privind parametrii hematologici la pui broiler trataţi cu Amoxidem 50\% Studies on hematological parameters in broiler chickens treated with 50\% Amoxidem. Medicamentul Veterinar, 5: 93-96. 